\title{
Productivity Optimization in a Fabrication Based Manufacturing unit using Industrial Management Principles
}

\author{
Adesh Kurhade, Prajkta Ninawe, Tinesh Borole, Venugopal Kulkarni
}

\begin{abstract}
The world is coming closer and closer day by day, globalization trends have opened doors for manufacturing outlets development in the country. To strive this competition the application of industrial tools and techniques theories has become vital. The fabrication based manufacturing factories have opened the doors for technological advancements to boon the profit levels. This paper deals with improvement of productivity through time and method study in the Fabrication based industry. The use of basic industrial management principles can result in huge improvements in the overall output of the system.The inappropriate planning and layout was countered with an effective one in order to get affirmative productivity results.

Keywords: Facility planning, Proper Layout, Material handling equipment, Time and Method study, Productivity, Fabrication industry.
\end{abstract}

\section{INTRODUCTION}

This project study was performed in Samarth Process Equipments that is a fabrication Based company that is located in Bhosari MIDC Block 15. There was an immense opportunity to learn about the actual production orocess and how an order gets converted into a finished product within no time. The supply and demand analysis that carved the whole industrial situation the amount of daily work the workers put in and finding the problems that were encountered that hindered the outputs and thus the productivity of the whole company. Thus we observed all the above mentioned things by visiting the industry on a regular weekly basis and tried to mark out the objectives by applying the industrial management principles in order to minimize wastes and optimize the productivity. The term productivity can take different meanings with the change in contexts. In a purely manufacturing based company the productivity can be defined as," Productivity is commonly defined as a ratio between the output volume and the volume of inputs. In other words, it measures how efficiently production inputs, such as labour and capital, are being used in an economy to produce a given level of output" by

Revised Manuscript Received on May 15, 2020.

* Correspondence Author

Adesh Kurhade*, School of Mechanical and Civil Engineering.MIT Academy Of Engineering,Pune. Email: arkurhade@mitaoe.ac.in

Prajkta Ninawe, School of Mechanical and Civil Engineering.MIT Academy Of Engineering,Pune. Email: pninawe@mitaoe.ac.in

Archana Bhange, School of Mechanical and Civil Engineering.MIT Academy Of Engineering,Pune. Email: asbhange@mitaoe.ac.in

Venugopal Kulkarni, School of Mechanical and Civil Engineering.MIT Academy Of Engineering

(c) The Authors. Published by Blue Eyes Intelligence Engineering and Sciences Publication (BEIESP). This is an open access article under the CC BY-NC-ND license (http://creativecommons.org/licenses/by-nc-nd/4.0/)
International Labours Organization. As an industrial engineer it is essential to find out the things that are hindering the overall output or not adding up anything in the whole system and need to be eliminated as soon as possible. Other than this one should also plan a continuous flow of resources in order to complete the objective before the deadline.

The problems that we were able to mark out included:

1. Stacking of the raw material in the working area

2. Unproductive lengthy travel of work piece from cutting to welding section

3. Excessive travel of the worker to the scrap

4. Unorganized finishing and dispatch section

5. Inappropriate material handling equipment between sections

6. Unplanned arrangements of the Manufacturing sections causing interuptions and bottlenecks in the flow pattern

In order to encounter these problems, revision and modification of current layout was crucial as many of the problems were indicating towards lack of facility planning and implementation. Also, to achieve employee satisfaction, modification is material handling equipment was important. Also as the company was medium scale based Production Company so it was difficult to bring in good quality and priced material handling equipment so a golden mean had to be found.

\section{Objectives of the Research:}

1. To obtain increased productivity by planning and implementing an efficient and organized Layout.

2. To minimize the unproductive and unnecessary travel of man, material, etc.

3. To minimize all kinds of wastes through the system.

4. To obtain worker and customer satisfaction

In order to get started we marked and sketched out the existing layout of the system and studied its problems that came into the picture due to its unplanned nature. 


\section{METHODOLOGY}

I.

CHANGE OF LAYOUT

In order to get started we marked and sketched out the existing layout of the system and studied its problems that came into the picture due to its unplanned nature.

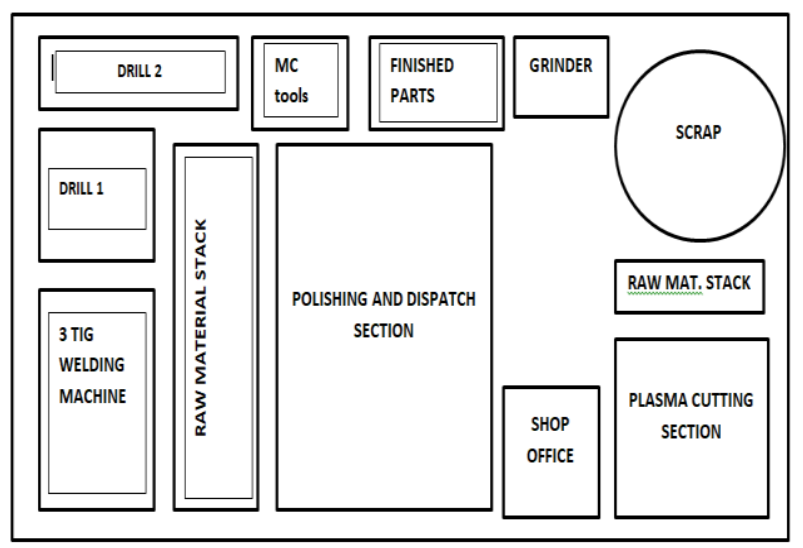

Fig 1- Existing Layout

The first and foremost problem that was seen was the distant placement of major machining sections.

The different travel patterns that averagely took place in the whole day included the following:

Table 1-Travel chart of material from different sections

\begin{tabular}{|c|c|c|c|c|}
\hline From & To & $\begin{array}{c}\text { Distanc } \\
\text { e } \\
\text { (sect,) }\end{array}$ & $\begin{array}{c}\text { Avg. } \\
\text { Pass/Da } \\
\text { (sect.) } \\
\text { ) }\end{array}$ & $\begin{array}{c}\text { Total } \\
\text { Dista } \\
\text { nce }\end{array}$ \\
\hline $\begin{array}{c}\text { Raw } \\
\text { Mat. }\end{array}$ & Cut & 8 & 12 & 96 \\
\hline Cut & Weld & 30 & 12 & 360 \\
\hline Weld & Scrap & 40 & 15 & 600 \\
\hline $\begin{array}{c}\text { MC } \\
\text { tool }\end{array}$ & Cut & 40 & 6 & 240 \\
\hline
\end{tabular}

The material in this industry is carried in batches of 30-40 work pieces from one section to the other with the help of workers. But the far distancing of the sections makes it time consuming. This time that is wasted during the travel of the material can be minimized and utilized for manufacturing that would definitely increase the output.

The travel of the worker along with the work piece on the trays clocks about 1 kilometers/hour. Thus, by adding up the travel from table- 1 we find out that the total time required for travel between sections is 77 minutes.

This can be done by improving the layout and cancelling out these large amounts of distances.

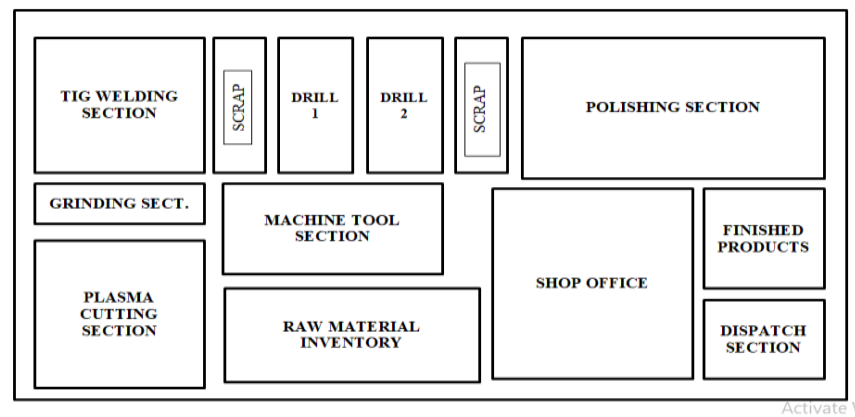

Fig 2- Proposed layout

Thus, by taking into consideration all kinds of enlisted problems an appropriate layout was designed by taking account of different industrial management principles

Now, the travel chart gets modified as shown :

Table 2- Revised travel-distance chart

\begin{tabular}{|c|c|c|c|c|}
\hline From & To & Distance & $\begin{array}{c}\text { Avg. } \\
\text { Pass/D } \\
\text { ay }\end{array}$ & $\begin{array}{c}\text { Total } \\
\text { Dista } \\
\text { nce }\end{array}$ \\
\hline $\begin{array}{l}\text { Raw } \\
\text { Mat. }\end{array}$ & Cut & 5 & 12 & 60 \\
\hline Cut & Weld & 10 & 12 & 120 \\
\hline Weld & Scrap & 2 & 15 & 30 \\
\hline $\begin{array}{c}\text { MC } \\
\text { tool }\end{array}$ & Cut & 5 & 6 & 30 \\
\hline
\end{tabular}

The revised travel chart now consists of the new layout in which the sections are closely placed together to eliminate all the unnecessary travel around the work place. The speed of the workers with material remains the same that is 1 kilometer/hour and then the total time required for the movement between workspaces is found to be 15 minutes.(approx.) which means about 62 minutes (1 hour 2 minutes) is saved due to shifting and implementation of the new layout. This saved time can be made available for manufacturing more number of components and hence increased output. Total time saved $=77$ minutes -15 minutes $=62$ minutes

The approx. time required for manufacturing one ideal fabrication component in SPE is 10 minutes which means about 6 more components daily. Thus, 256 extra components can be manufactured on a monthly basis by just implementing the proposed layout.

\section{i. Changing Material handling equipment}

The current material handling equipment that was employed for moving the material within the work places was a pallet that had to be manually pulled and thus the speed of transferring the components was slow as a small amount of components were able to be carried at a time. An average of about 4 components was carried at a time in this pallet. This meant that the pallets had to travel more number of rounds.

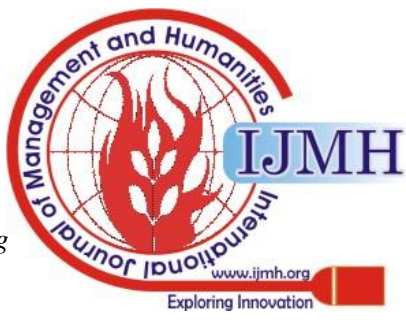




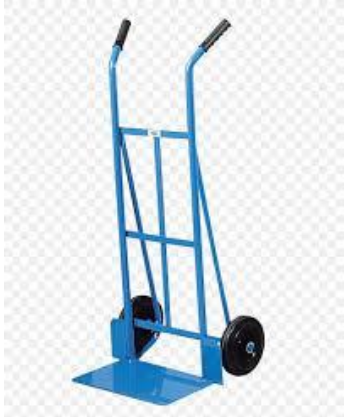

Fig 3- Pallet

The average number of components produced daily was 120 which according to the current capacity meant 30 rounds.

This distance travelled in the form of rounds can be minimized by analyzing the whole problem by the 5 whys technique. This technique is very helpful in going to the root cause of the problem.

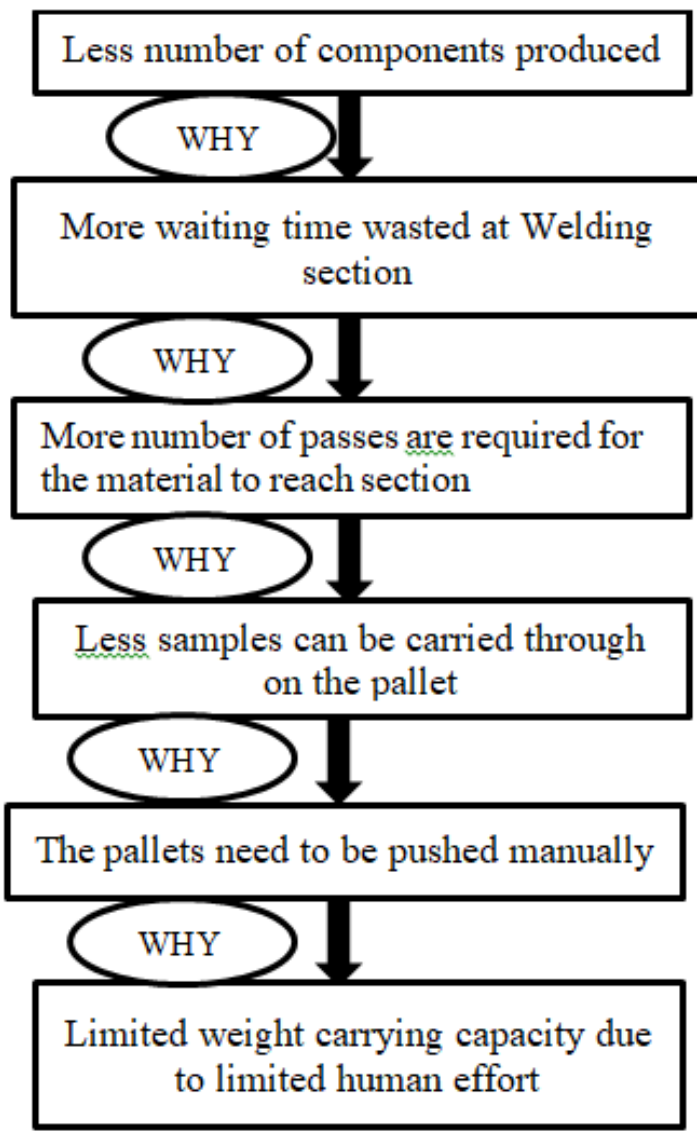

Fig 4- 5 whys technique

After the application of 5 Whys technique it is found out that the root cause for propagation of the problem is the limited weight carrying capacity of the humans. The humans can push up to 10 components (max.) on the pallet between two sections. If this human effort was to be replaced by a small power driven vehicle or trolley type equipment then it will be able to carry more amount of components during a pass. So we suggested a power driven vehicle with an extended pallet attachment as shown in fig -5 .

This type of material handling equipment can carry about 20 components at a time. This means almost double components can be carried at a time and the rounds are minimized to 15 now which mean half of the time saved due to the proposed material handling equipment.

\section{ii. $\quad$ Raw Material Stacking}

Another problem that was observed included stacking of the material at various sections including the polishing and finished part section due to absence of a separate raw material inventory where everything could be stored specifically. It was also observed that there was an absence of a storing equipment to hold all the material together in an organized way. Also many of the waste and scrap material was found to be lying along with the raw material stacks. The above mentioned problems can be solved by assigning a proper inventory as it has been done in the proposed layout. The second problem can be handled by applying the $5 \mathrm{~s}$ theory of industrial engineering.

THE 5 PILLARS OF WORKPLACE ORGANIZATION

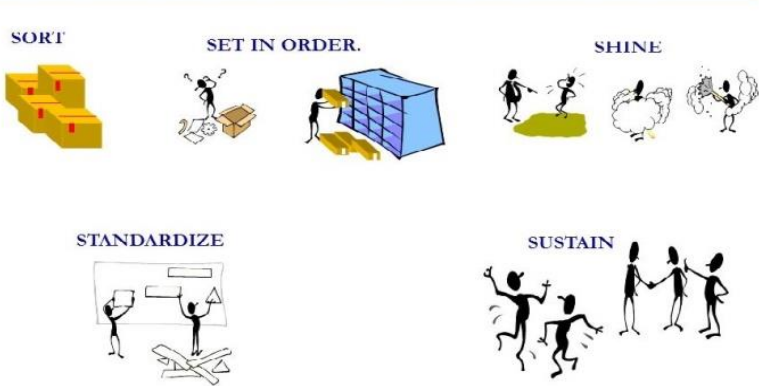

Fig 6- The 5 S methodology

The proposed methodology includes:

i. Sort- sorting of the raw material and separating it from the other wastes and scraps is to be done.

ii. Set in order- proper organization of the incoming raw material should be done in storage device suc as the shelves.

iii. Shine- in order to keep the work place hygienic and organized it should be cleaned daily

iv. Standardize- Make your processes coincide with the standardly accepted procedures.

v. Sustain- consistency in the maintenance of the given principles is the key to success.

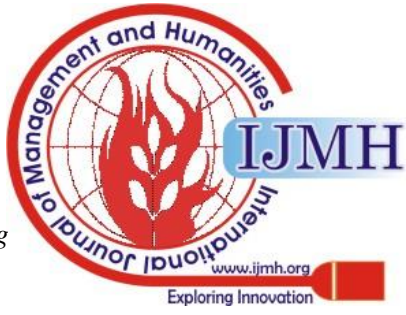




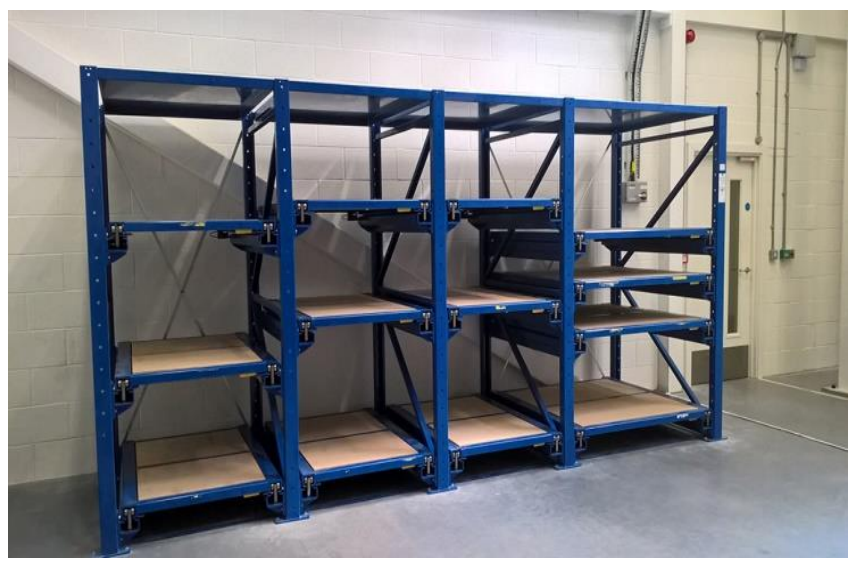

Fig 7- Shelves for storing Raw materials

\section{III- RESULTS}

Thus , the productivity increment has been found out to be:

Table 3- Productivity Increment

\begin{tabular}{|l|l|l|l|}
\hline \multicolumn{1}{|c}{ Table 3- Productivity Increment } \\
\hline & $\begin{array}{l}\text { Parts } \\
\text { made }\end{array}$ & $\begin{array}{l}\text { Profit/ } \\
\text { part }\end{array}$ & $\begin{array}{l}\text { Total } \\
\text { turnover }\end{array}$ \\
\hline Existing & 14400 & 450 & $64,80,000$ \\
\hline Proposed & 17472 & 450 & $78,62,400$ \\
\hline
\end{tabular}

Hence,

Total profit made $=78,62,400-64,80,000$ $=13,82,400 ₹$

Profit increment $=13,82,400 / 64,80,000$

$$
=\mathbf{2 1 . 3 3 \%}
$$

Thus, by the application of proposed industrial management techniques a profit increment of $21.33 \%$ can occur.

\section{CONCLUSIONS AND DISCUSSIONS}

The performance of the whole industry is largely related to the cost factor that is each and everything is coming down to cash inflows and profitable outflows. The changes that are suggested in this paper are temporarily based for the standard boiler components that they are fabricating and the whole study was done by taking the same into consideration.

Other modifications can also be possible in the working are including better lighting and improved quality of restrooms for the workers by taking into account the ergonomical considerations as they also have an impact on the productivity of a firm. These changes cannot be applied currently due to huge investments that will be required in the implementation of the proposed layout and the replacement of more material handling equipment i.e. the vehicle extended pallets. Also purchasing of shelves will help the raw material inventory to be organized in a proper way eliminating the stacking and mixture that was earlier taking place.

The utilization of resources to their fullest and minimizing the unproductive stuff from the industrial processes is the major key in gaining profits. The unnecessary travel of man and the material was eliminated by shifting to the proposed layout that was made taking this wastage into consideration.

Thus, it can now be proved that the implementation of facility planning and management tools can help to improve the productivity of a firm.

\section{REFERENCES}

1. Mihir B Patel, Prof. Dr. Hemant R. Thakkar, they work on "Reducing Manufacturing Cycle Time of Milk Tanks by Work Study

2. Technique in Small Scale Fabrication Industry." (DOI:10.15680/IJIRSET. 2015. 0412163).

\section{AUTHORS PROFILE}

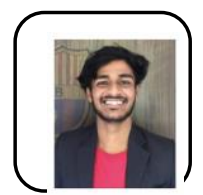

Adesh Kurhade, A student pursuing BTech in Mechanical Engineering in MIT Academy of Engineering, Pune from 2018. Completed Diploma in Mechanical Engineering from Government Polytechnic, Pune with first class Distinction. Achieved 'Best Project Award' in 2018 for the project Automatic Color Sorting System at FESTALK. The group leader in the HVAC lab maintenance in GP Pune. Won Student of the year in class X-CBSE .

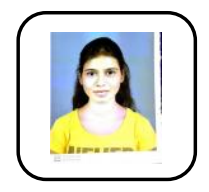

Prajkta Ninawe, currently pursuing her Btech in Mechanical Engineering from MIT academy of Engineering Pune. She completed her diploma from GP Nagpur with Distinction. Won the 'creative project idea award' at diploma level for making the 3d printing machine.she was Innvolved in working on the study of engineering materials using composite wall structures at MITAOE in 2019.

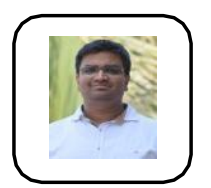

Tinesh Borole, he is currently pursuing his bachelors degree from MIT academy of engineering, Pune. He completed his diploma with distinction from KK wagh college of engineering.He won the 'best project award' at FESTALK for the project Automatic color sorting system. He was involved in projects like multipurpose drilling machine, Arduino based water alarm. He is currently working on Multi-directional conveyor belt system.

Venugopal Kulkarni Working as Assistant Professor in MIT Academy of Engineering, Pune from June 2016. Associated with Institution of Mechanical Engineers (IMechE), UK since December 2016. Working as Industrial consultant in Chakan, Pune Industrial area for activities like training, quality since 2016. 